\title{
Competition of hydrogen bonds and coordinate bonds induces a reversible crystal transformation
}

\author{
Peng Meng ${ }^{\dagger}$, Aidan Brock ${ }^{\dagger}$, Xiaodong Wang $g^{\dagger}$, Yanan X $u^{+}$, John McMurtrie ${ }^{\dagger}$, Jingsan X $u^{\dagger} *$ \\ ${ }^{\dagger}$ School of Chemistry and Physics, Science and Engineering Faculty, Queensland University of \\ Technology, Brisbane, QLD 4000, Australia \\ $\$$ Central Analytical Research Facility, Institute for Future Environments, Queensland University \\ of Technology, Brisbane, QLD 4000, Australia \\ *Email: Jingsan.Xu@qut.edu.au
}

\section{Materials synthesis, characterization and measurement}

\subsection{Materials}

Melamine ( $\geq 99 \%$, Sigma-Aldrich), Cyanuric acid (( $\geq 98 \%$, Sigma-Aldrich), Silver nitrate ( $\geq 99.5 \%$, Chem-Supply), and ammonia solution (30\% in water, Chem-Supply) were used as received without further purification. Ultrapure water was used in all experiments $(18.2 \mathrm{M} \Omega \cdot \mathrm{cm}$, Synergy UV Water Purification System, Merck Millipore). The solutions of melamine (20 $\mathrm{mmol} / \mathrm{L})$, cyanuric acid $(20 \mathrm{mmol} / \mathrm{L})$, silver nitrate $(20 \mathrm{mmol} / \mathrm{L})$, and aqueous ammonia $(10 \mathrm{wt} \%)$ were prepared in the laboratory.

\subsection{Crystallization of Ag-block}

Ammonia $(0.5 \mathrm{~mL}, 10 \%)$ was added to $0.5 \mathrm{~mL}$ aqueous cyanuric acid solution $(20 \mathrm{mM})$. Then, $0.5 \mathrm{~mL}$ of aqueous melamine solution $(20 \mathrm{mM})$ was added followed by $0.5 \mathrm{~mL}$ aqueous silver nitrate solution $(20 \mathrm{mM})$. Fibrous product was observed within minutes. The vial was capped and put in a dark closet at room temperature. Crystalline blocks of $\mathbf{2}$ were observed to form over 2-3 months. Elemental analysis calculated for $\mathrm{C}_{6} \mathrm{H}_{12} \mathrm{AgN}_{9} \mathrm{O}_{5}: \mathrm{C} 18.10 \%, \mathrm{H} 3.04, \mathrm{~N}$ 31.67, O 20.10; found: C $18.07 \%$, H 2.96\%, N 31.27\%, O $18.91 \%$.

\subsection{Characterization}

For scanning electron microscopy (SEM), the sample was coated by gold and observed on a Tecan Mira3 operated at an accelerating voltage of $5 \mathrm{kV}$. 
The powder X-ray diffraction (XRD) patterns were obtained in Debye-Scherrer geometry on a Rigaku Smartlab diffractometer using $\mathrm{Cu} \mathrm{K \alpha}$ radiation $(\lambda=1.5406 \AA)$ working at $40 \mathrm{~mA}$ and 40 $\mathrm{kV}$. The powdered samples were packed in $\varphi 0.3 \mathrm{~mm}$ capillaries and constantly spun at $15 \mathrm{rpm}$ during data collection. A focusing mirror in CBO-e module converges X-ray to a Hypix3000 detector working in $1 \mathrm{D}$ mode. The powder pattern was collected from 5 to $155^{\circ}(2 \theta)$ with a step size of $0.02^{\circ}(2 \theta)$.

The mid infrared spectrum (IR) was collected with a Nicolet iS50 FTIR spectrometer with a resolution of $4 \mathrm{~cm}^{-1}$.

The thermogravimetric (TG) curves were collected on NETZSCH STA 449F3 under $\mathrm{N}_{2}$. The heating speed is $5^{\circ} \mathrm{C} / \mathrm{min}$.

\section{4. $\mathrm{Ag}^{+}$and melamine concentration determination}

The sample at different reaction stages was filtrated out. The filtrate was covered with aluminum foil and sent to inductively coupled plasma optical emission spectrometry (ICP-OES) for $\mathrm{Ag}^{+}$concentration determination.

The melamine concentration was determined by the following method. The experiments were scaled and performed in a large bottle $(100 \mathrm{~mL})$. The solution $(50 \mathrm{~mL})$ was filtrated out and put on a petri dish with a known weight. The petri dish was then transferred into an oven at $80{ }^{\circ} \mathrm{C}$ to allow the water to evaporate. As water evaporated, CAM particles would form. After the solution was completely dried, the petri dish was then weighted again to calculate the mass of the left solids (CAM), from which the mole can be calculated. The concentration of melamine or cyanuric acid was then derived by dividing the volume by the moles.

\subsection{Single crystal $X$-ray structure determination}

A single crystal of $\mathbf{2}$ was coated in Paratone $\mathbf{N}$ oil and mounted on a nylon loop for collection. SCXRD data was collected on the MX1 beamline at the Australian Synchrotron $^{1}(\lambda=$ $0.7108 \AA, \mathrm{T}=100 \mathrm{~K})$. Data was processed in CrysAlis Pro. ${ }^{2}$ A structure solution was obtained using SHELXT ${ }^{3}$ and refined using SHELXL ${ }^{4}$ implemented within the Olex2 graphical interface. $^{5}$ 
All full-occupancy non-hydrogen models were refined anisotropically, while hydrogen atoms were placed in idealized positions and refined using a riding model on appropriate atoms. Crystal structure data has been deposited with the CCDC (deposition number 2092693).

\subsection{Wide-Range Reciprocal Space Mapping (WR-RSM)}

A single crystal (size $50 \mu \mathrm{m} \times 500 \mu \mathrm{m}$ ) of 2 does not show clear Kukuchi bands in EBSD (Electron Back-Scattering Diffraction). The diffraction signals of the crystal have been measured using X-ray beam for its deeper penetration depth hence larger interaction volume, comparing to electron beam. The single crystal was glued on a glass slide, which was mounted on a Eulerian cradle ( $\chi-\varphi$ stage) of a Rigaku SmartLab Diffractometer, in such way that the long axis of the crystal is parallel with the goniometer axis. A poly-capillary optic in CBO-f module was used to converge parallel beam from the $\mathrm{CBO}$ module to point focus which was further tailored using a $\varphi 0.5 \mathrm{~mm}$ collimator snout. The single crystal was placed in the cradle centre and been aligned in the goniometer centre. A Hypix3000 detector placed $\sim 120 \mathrm{~mm}$ away from the single crystal was used to collect the diffraction pattern of the single crystal at different $\chi$ tilt in 2D-TDI mode.

The series of frames collected were chi expanded in Rigaku 2D Data Processing and were plotted in Reciprocal Space using Rigaku 3D Explore software, as shown in Figure 4c. It is easy to see the crystal has an orthorhombic unit cell. The periodicity in the long axis direction $(3.33 \AA)$ and in the thickness direction $(19.5 \AA)$ of the single crystal can also be directly read out from Figure 4c. These values match with $d_{200}$ and $d_{002}$ calculated from the unit cell. Each of the reciprocal spot represents a series of crystal planes, whose Miller index is also labelled in Figure 4c. It is therefore confirmed that the long axis direction of the crystal is in $a$ axis, while the $\mathrm{Z}$ height direction of the crystal is in $c$ axis (Figure 4c, inset).

\subsection{Mechanical tests by nanoindentation}

A Hysitron TI 950 Nanoindentor was used for the mechanical tests of crystal 2. To measure the elastic modulus, nanoindentation tests were performed using a Berkovich indenter (threesided pyramidal indenter with a tip radius of approximately $150 \mathrm{~nm}$ and included angle of $142.3^{\circ}$ ) 
at room temperature. The tip area function of the Berkovich indenter was carefully calibrated on the fused quartz with known reduced modulus $(69.6 \mathrm{GPa} \pm 5 \%)$ and hardness $(9.25 \mathrm{GPa} \pm 10 \%)$. The depth profile of crystal 2 (differences or similarities in elastic modulus with respect to depth) is obtained by a partial unloading. During nanoindentation tests, the load and displacement were real-time recorded, from which reduced modulus $E$ can be calculated based on the Oliver-Pharr method (Equation S1): ${ }^{6}$

$$
\left.E=\frac{\sqrt{\pi}}{2} \frac{S}{\sqrt{A}} \quad \text { (Equation } \mathrm{S} 1\right)
$$

where, $S$ is the measured stiffness, $A$ is the contact area. 


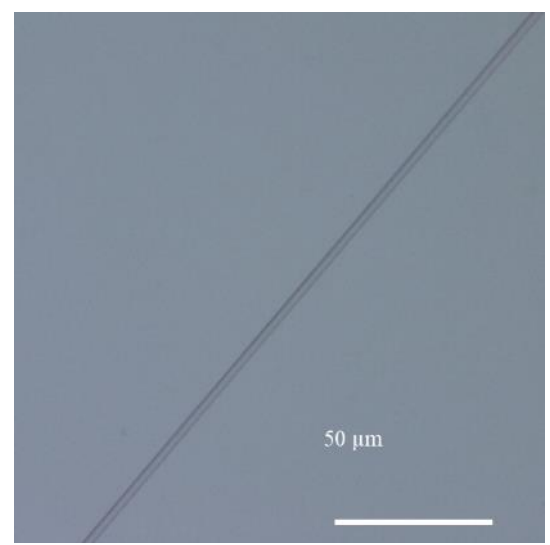

Figure S1. Light microscopic image of a single crystal 1.
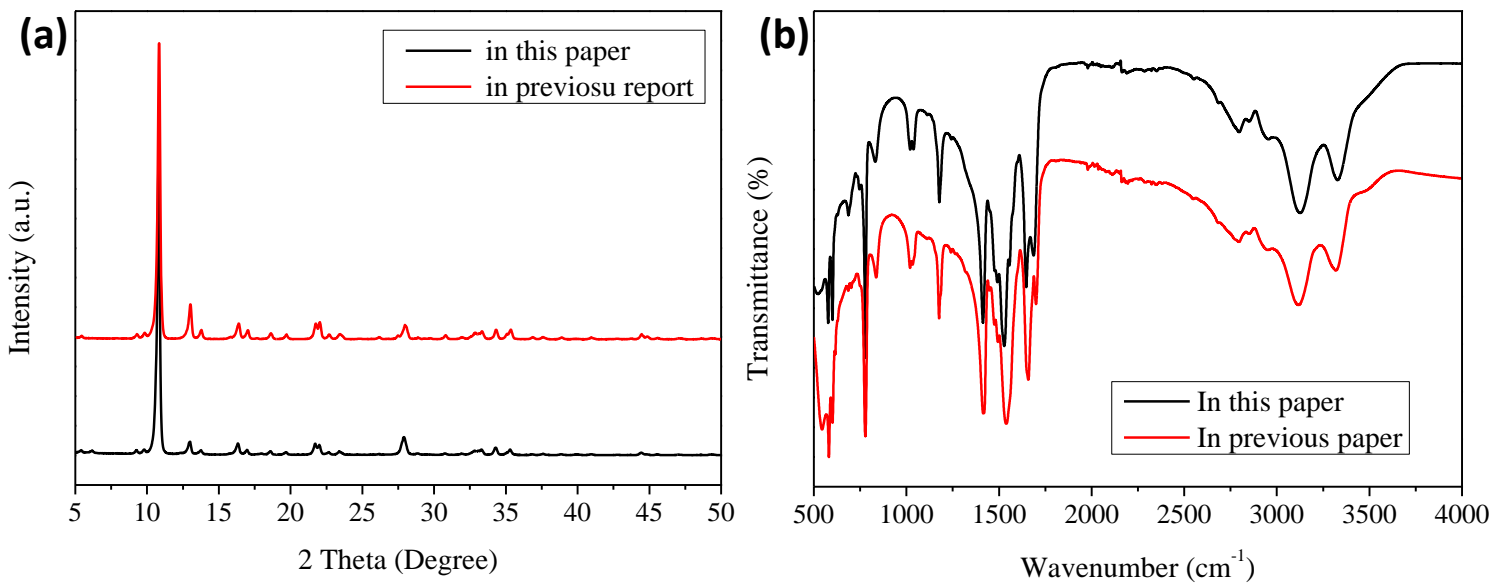

Figure S2. (a) XRD patterns of crystal 1 in this paper and the fiber in our previous report. ${ }^{7}$ (b) the corresponding IR spectra.
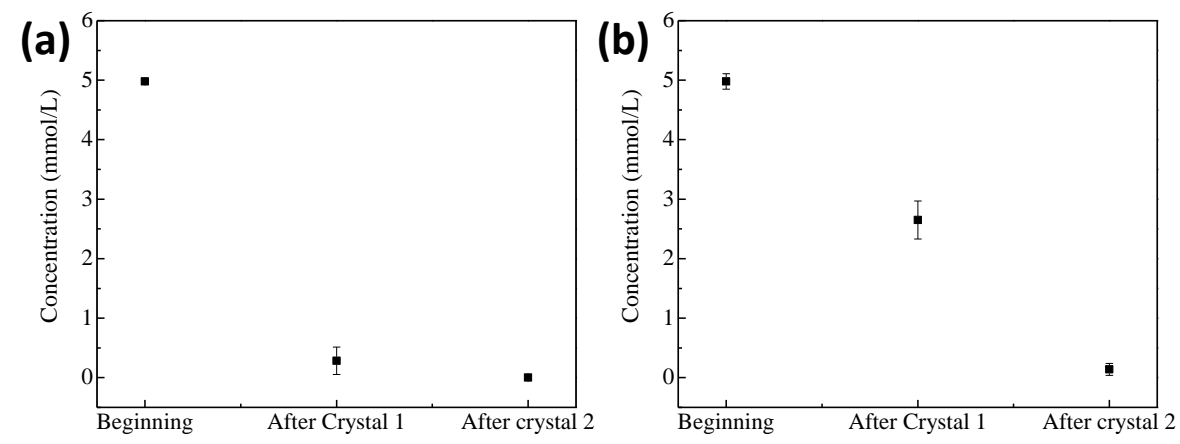

Figure S3. (a) $\mathrm{Ag}^{+}$concentration and (b) melamine (cyanuric acid) concentration in the reaction system at different stages. 


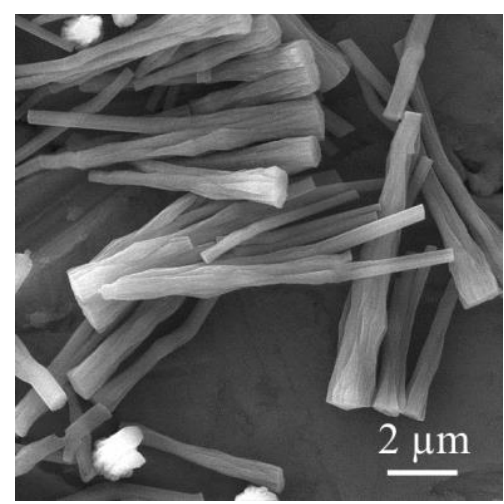

Figure S4. SEM image of CAM particles formed by the remaining CA and M after filtration.
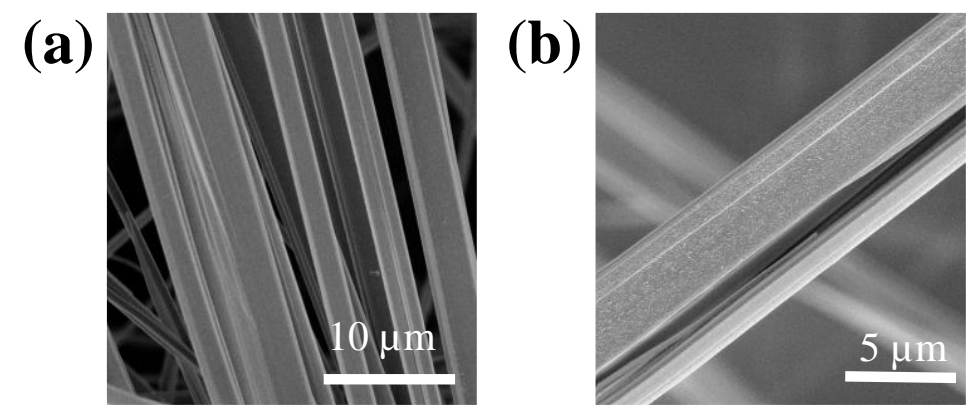

Figure S5. (a,b) SEM images of re-formed crystal 1 fibers by keeping $\mathrm{Ag}^{+}$in crystal $\mathbf{2}$.
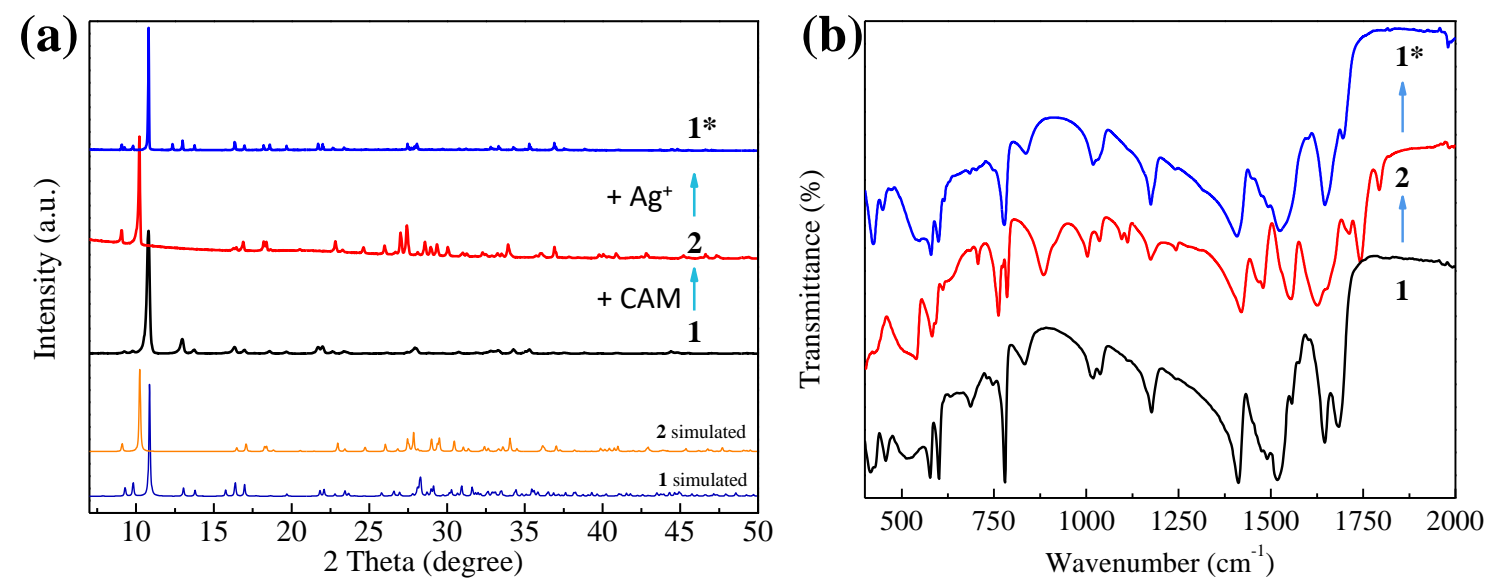

Figure S6. (a) XRD and (b) FTIR spectra of crystal 1 re-formed (1*) by adding $\mathrm{Ag}^{+}$into crystal 2. 


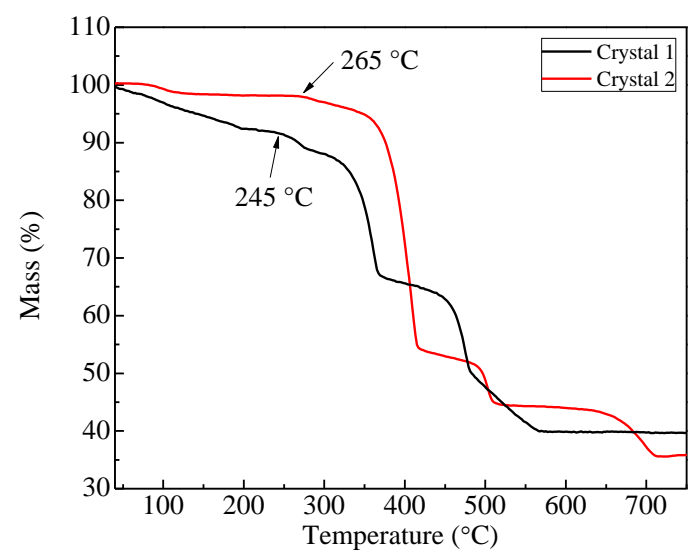

Figure S7. Thermogravimetric curves of crystal 1 and 2.
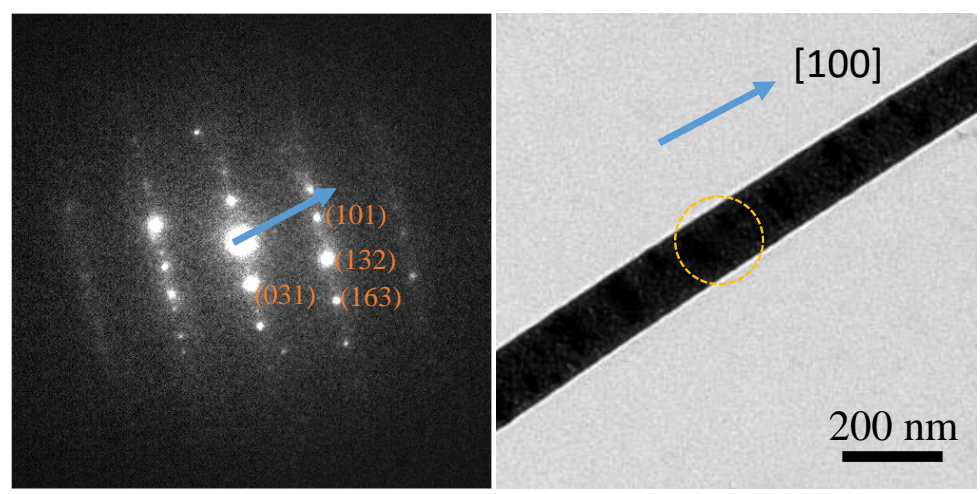

Figure S8. SAED image (left) and the corresponding TEM image (right—circled is the diffracted area) of a single crystal 1 for face-indexing.
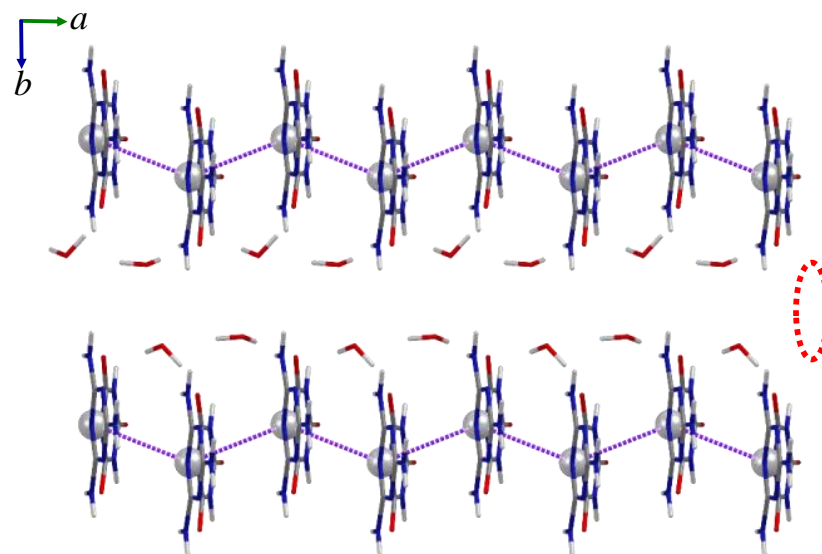

Figure S9. Structure of crystal 2 viewing along [001]. 


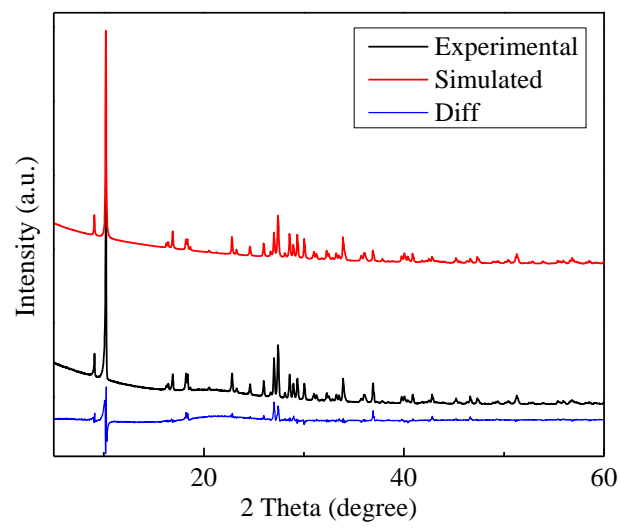

Figure S10. Calculated and experimental PXRD patterns of crystal 2.

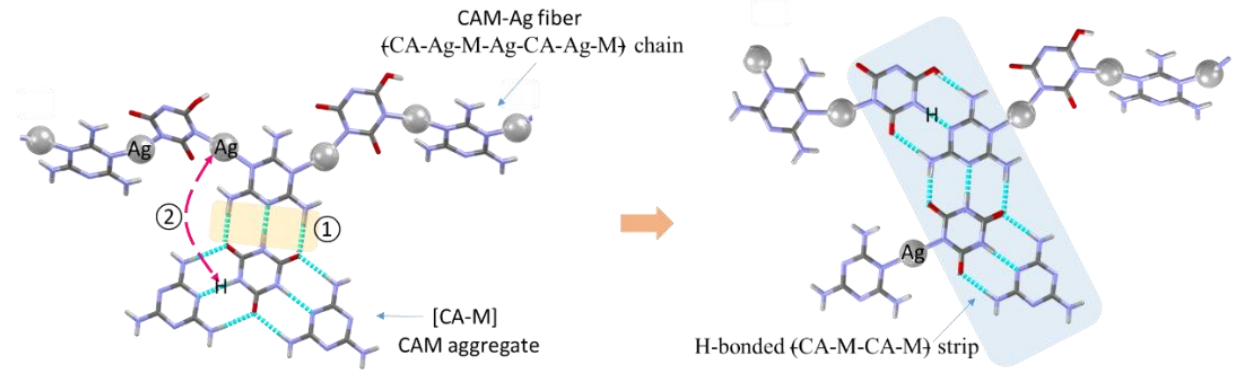

Figure S11. Illustration of proposed mechanism for crystal $\mathbf{1}$ integrating CAM aggregate.

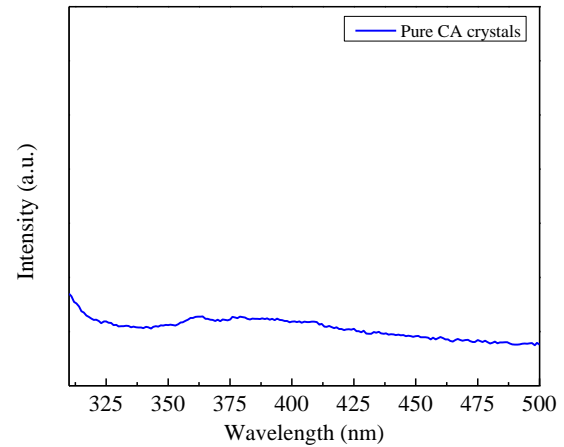

Figure S12. PL emission spectra of pure CA crystals under exciation of light at $300 \mathrm{~nm}$.

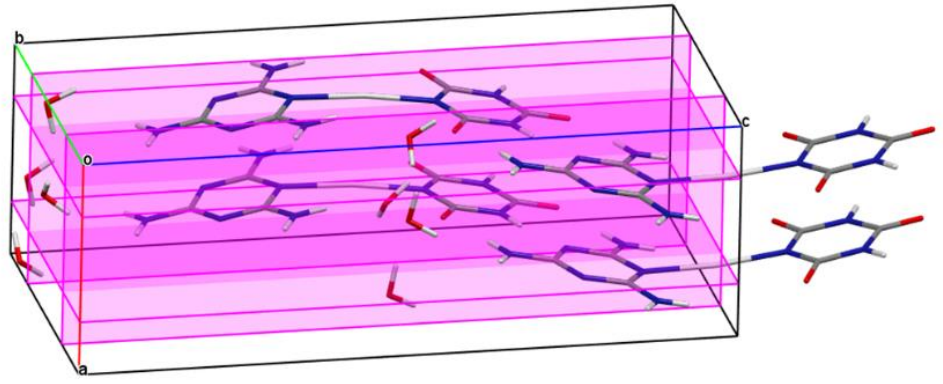

Figure S13. Illustration of glide planes (colored pink) in crystal 2. 
Table S1. Crystal data and structure refinement for $\mathbf{2}$.

\begin{tabular}{|c|c|}
\hline Empirical formula & $\mathrm{C}_{6} \mathrm{H}_{12} \mathrm{AgN}_{9} \mathrm{O}_{5}$ \\
\hline Formula weight & 398.12 \\
\hline Temperature/K & $100(2)$ \\
\hline Crystal system & orthorhombic \\
\hline Space group & Pna2 1 \\
\hline $\mathrm{a} / \AA$ & $6.4910(13)$ \\
\hline $\mathrm{b} / \AA$ & $9.6390(19)$ \\
\hline $\mathrm{c} / \AA$ & $19.409(4)$ \\
\hline$\alpha /^{\circ}$ & 90 \\
\hline$\beta /{ }^{\circ}$ & 90 \\
\hline$\gamma /{ }^{\circ}$ & 90 \\
\hline Volume $/ \AA^{3}$ & $1214.4(4)$ \\
\hline $\mathrm{Z}$ & 4 \\
\hline$\rho_{\text {calc }} \mathrm{g} / \mathrm{cm}^{3}$ & 2.178 \\
\hline$\mu / \mathrm{mm}^{-1}$ & 1.705 \\
\hline $\mathrm{F}(000)$ & 792.0 \\
\hline Crystal size $/ \mathrm{mm}^{3}$ & $1 \times 0.05 \times 0.02$ \\
\hline Radiation & Synchrotron $(\lambda=0.7108)$ \\
\hline $2 \Theta$ range for data collection $/{ }^{\circ}$ & 4.198 to 59.616 \\
\hline Index ranges & $-8 \leq \mathrm{h} \leq 8,-13 \leq \mathrm{k} \leq 13,-24 \leq 1 \leq 24$ \\
\hline Reflections collected & 17002 \\
\hline Independent reflections & $3093\left[R_{\text {int }}=0.0208, R_{\text {sigma }}=0.0126\right]$ \\
\hline Data/restraints/parameters & $3093 / 1 / 198$ \\
\hline Goodness-of-fit on $\mathrm{F}^{2}$ & 1.068 \\
\hline Final R indexes $[\mathrm{I}>=2 \sigma(\mathrm{I})]$ & $\mathrm{R}_{1}=0.0235, \mathrm{wR} 2=0.0621$ \\
\hline Final $\mathrm{R}$ indexes [all data] & $\mathrm{R}_{1}=0.0250, \mathrm{wR}_{2}=0.0633$ \\
\hline Largest diff. peak/hole / e $\AA^{-3}$ & $0.98 /-0.86$ \\
\hline
\end{tabular}




\section{References}

1. Cowieson, N. P.; Aragao, D.; Clift, M.; Ericsson, D. J.; Gee, C.; Harrop, S. J.; Mudie, N.; Panjikar, S.; Price, J. R.; Riboldi-Tunnicliffe, A.; Williamson, R.; Caradoc-Davies, T., MX1: a bending-magnet crystallography beamline serving both chemical and macromolecular crystallography communities at the Australian Synchrotron. J. Synchr. Rad. 2015, 22, 187-190.

2. Diffraction, R. O. CrysAlis Pro, 40_64.53a; Rigaku Oxford Diffraction: 2019.

3. Sheldrick, G. M., SHELXT - Integrated space-group and crystal-structure determination. Acta Cryst. A 2015, 71, 3-8.

4. Sheldrick, G. M., A short history of SHELX. Acta Cryst. A 2008, 64, 112-122.

5. Dolomanov, O. V.; Bourhis, L. J.; Gildea, R. J.; Howard, J. A. K.; Puschmann, H., OLEX2: a complete structure solution, refinement and analysis program. J. Appl. Cryst. 2009, 42, 339341.

6. Oliver, W.; Pharr, G., An Improved Technique for Determining Hardness and Elastic Modulus Using Load and Displacement Sensing Indentation Experiments. J. Mater. Res. 1992, 7, 15641583.

7. Meng, P.; Brock, A.; Xu, Y.; Han, C.; Chen, S.; Yan, C.; McMurtrie, J.; Xu, J., Crystal Transformation from the Incorporation of Coordinate Bonds into a Hydrogen-Bonded Network Yields Robust Free-Standing Supramolecular Membranes. J. Am. Chem. Soc. 2020, 142 (1), 479-486. 